\title{
Materials in the Moscone (If the Walls Could Talk)
}

The Moscone West Convention Center in San Francisco, the new home to the technical sessions of the MRS Spring Meeting, adds an intriguing dimension to our Meeting: Not only does it house the meeting, the building itself is part of the program! Glass, metal, concrete-it all speaks of advanced materials. To start, the enormous "curtain wall" that forms the bulk of the exterior is made almost entirely of glass. However, this is not your grandfather's hardware-store window glass. The glass had to be suspended from exposed structural steel as an assembly of hundreds of nearly continuous 10 -foot panels. Situated directly in the hotel and entertainment district where we have always held our San Francisco meetings, the Moscone West was constructed with a type of glass designed to direct a comfortable level of daylight into as many meeting spaces as possible. It also emits a satisfying glow to the exterior from the indoor lighting at night, minimizes undesirable solar heating, and provides thermal insulation.

According to Heather Beck of Viracon, the manufacturer of the glass, the panels are actually bilayers of heat-treated glass, coated on the inside surface with "Solarscreen 2000." Solarscreen 2000 consists of thin, durable metal coatings applied to float-glass substrates using magnetron-sputtered vacuum-deposition

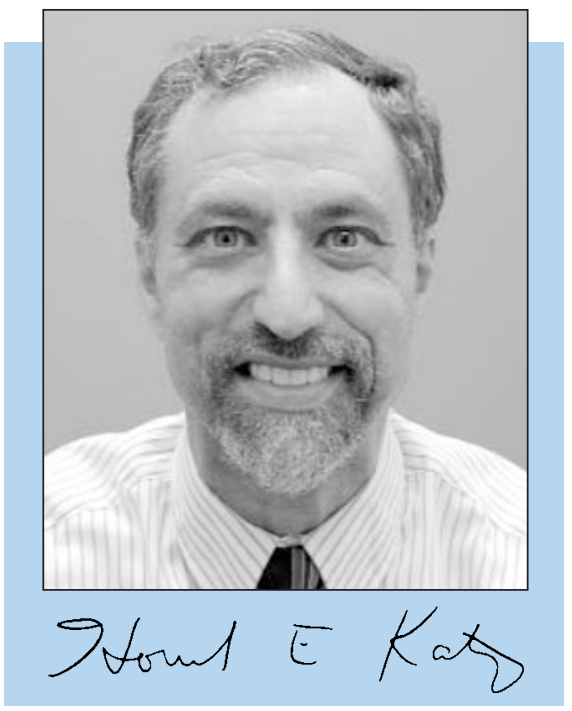

technology. Each glass substrate offers specific performance characteristics, which vary according to the thickness of the glass or the specific fabrication process. The glass used in the Moscone allows 85-90\% of the outside visible light that ordinary glass would allow into the building from outside, but cuts solar heating by $30 \%$.

Another interesting architectural material used in the convention center is quartzite. Though nominally of the same elemental composition as glass, it is, of

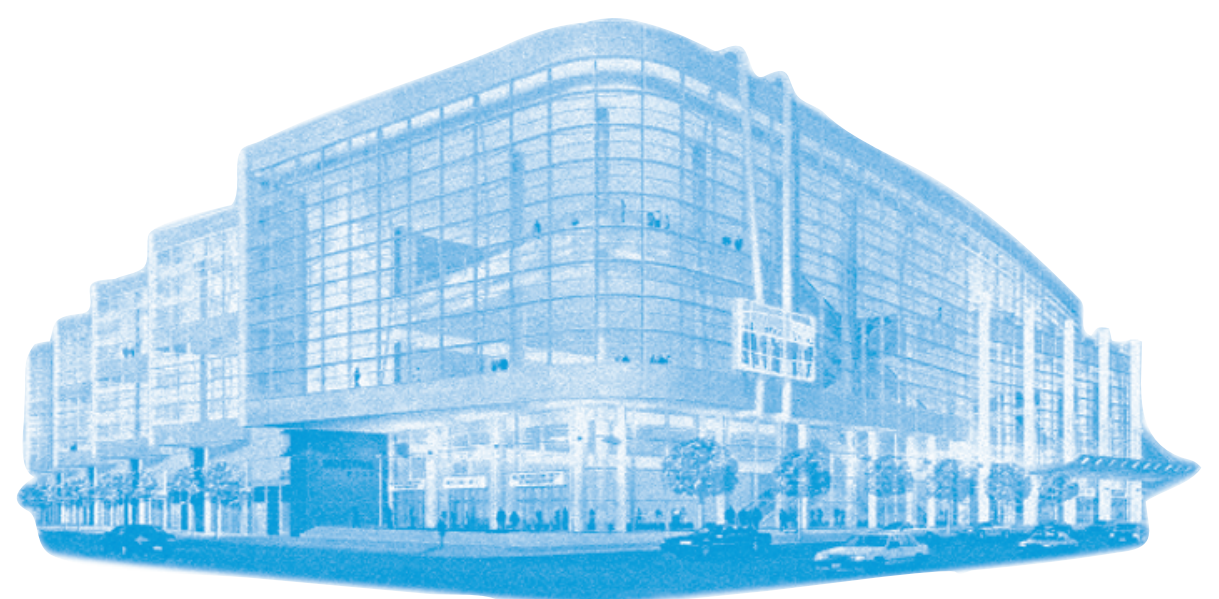

For a Virtual Tour of the Moscone West Convention Center, access http://www.sfvisitor.org/convention/html/moscvirt.html course, an entirely different substance in every other respect. The result of the metamorphosis of sandstone under heat and pressure, quartzite is a hard and dense material with a great variety of surface textures and dopant-induced colors. Quartzite was chosen for the interior wall that leads from the front of the building to the activity and meeting rooms.

Architectural precast concrete was used to form the panels that make up the opaque portions of the outer walls. The pleasing color and desired texture were imparted by techniques including pigment incorporation, acid etching, and controlled sandblasting, according to information provided by Thomas Ketron of Clark Pacific, a producer of precast concrete. If we substitute higher-tech terms like chromophore blending, reactive-ion etching, and chemical-mechanical polishing, it becomes apparent to those who did not already realize it how high-tech a material cement really is!

To minimize mechanical stresses resulting from vibrations and settling, the building support structures include friction dampers, sets of metal plates bolted together with flat surfaces in contact, that can rotate with respect to each other in response to stress. There are a total of 248 of them, most of which are hidden behind the partition walls, but a few of which are visible around staircases. According to Avtar Pall of Pall Dynamics, the supplier of these dampers, specially treated steel and bronze surfaces are used to maximize the amount of the strain energy that is dissipated through sliding friction, leaving much less energy acting to distort the frame of the building. It is anticipated that creep in the frame could amount to several percent over the life of the building.

The transparent front facing of the Moscone lets us feel that we are always part of the life of the city, and it invites passersby to share in the vibrancy of the meeting being held within. As we feast on the menu of cutting-edge symposia, special presentations, and nonstop networking opportunities that we have come to expect at an MRS Meeting, let us also take in the materials around us that enabled the construction of such a multifunctional and attractive facility.

HOWARD E. KATZ 2004 MRS President 